\title{
Performance Improvement of Electrical Power System using UPFC Controller
}

\author{
Ghazanfar Shahgholian*, Mohammad Reza Yousefi \\ Smart Microgrid Research Center, Najafabad Branch, Islamic Azad University, Najafabad, Iran
}

*Corresponding Author: Ghazanfar Shahgholian, Smart Microgrid Research Center, Najafabad Branch, Islamic Azad University, Najafabad, Iran

\begin{abstract}
A flexible ac transmission system (FACTS) controller can play an important role in mitigating voltage stability problems and power transfer capability. The unified power flow controller (UPFC) is one of the FACTS controller that combines both series and shunt compensators, and offers more specific characteristics compared to other devices controller. In this paper, a UPFC is applied to improve dynamic performance of electrical power system by using power flow control. Phasor model of UPFC is used. All the simulations for this work have been carried out using MATLAB/SIMULINK environment.
\end{abstract}

Keywords: Power flow control, FACTS controller, UPFC.

\section{INTRODUCTION}

In general, transmission lines are under-utilized and uncontrolled [1,2]. The line impedance, the receiving and sending ends voltages, and phase angle between the voltages determine the transmitted electrical power over a line [3,4]. Various types of flexible ac transmission system (FACTS) devices are employed to control different parameters of the transmission system, such as line impedance, voltage magnitude and voltage phase angle [5,6]. They also both enhancing controllability and increasing power transfer capacity of electric power transmission networks.

In general, FACTS controllers can be divided into four categories based on their connection in the network as shown in Fig. 1: series controllers, shunt controllers, combined series-series controllers and combined series-shunt controllers. Static synchronous compensator (STATCOM) [7,8] and static synchronous series compensator (SSSC) $[9,10]$ are one-port controller and unified power flow controller (UPFC) $[11,12]$ and interline power flow controller (IPFC) $[13,14]$ are two-port controller.

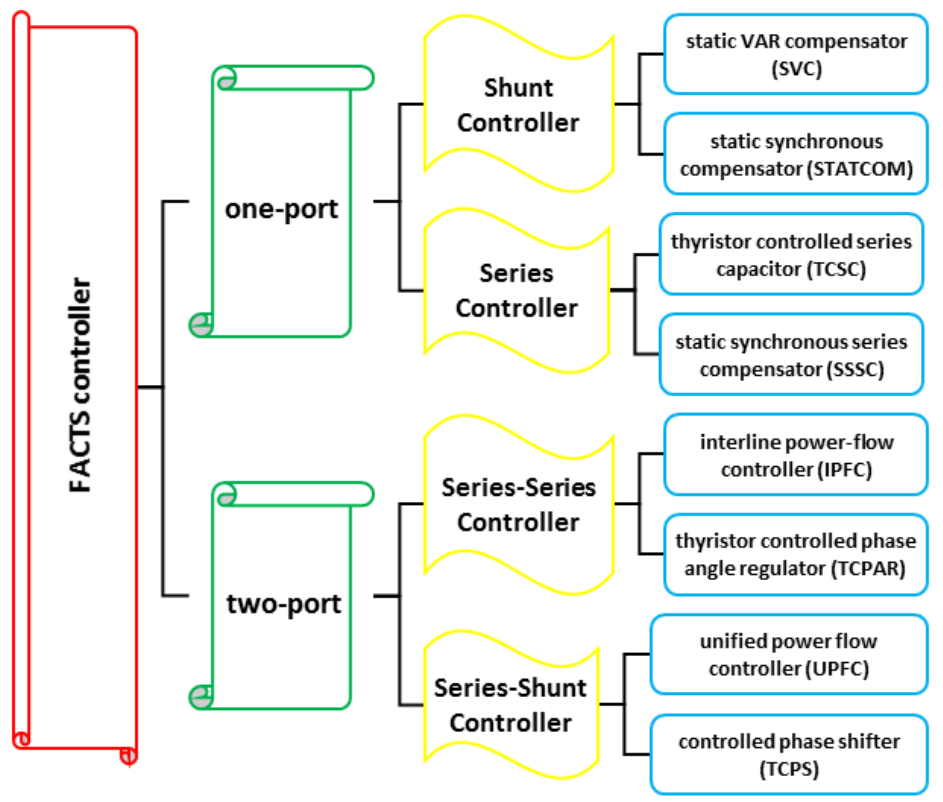

Fig1. Overview of major FACTS devices base on their connection 
In summary, FACTS devices are used to achieve the following major goals: control power flow along desired transmission corridors, increase transmission capacity without requiring new transmission infrastructure, improve dynamic stability, transient stability and voltage stability of the system, and provide damping for inter-area oscillations $[15,16]$.

Power generation and transmission is a complex process, wherever power is to be transferred, the two main components are active and reactive power. The UPFC is the most versatile and complex power electronic equipment that has emerged for the control and optimization of power flow in electrical power transmission system $[17,18]$. It is one of the series shunt controllers.

Several references in technical literature can be found on utilizing UPFC in power system [19,20]. A stochastic-based approach to determine the optimal sizing of two FACTS shames in a power system for steady-state voltage profile enhancement is presented in [21], which TCSC and UPFC are employed in the power system to adjust the natural power sharing of two different parallel transmission lines and therefore enable the maximum transmission capacity to be utilized. The application of the decentralized modal control method for pole placement in multi-machine power system utilizing FACTS devices such as UPFC is developed in [22]. A coordinated design between power system stabilizer (PSS) and a UPFC using genetic algorithms is presented in [23], which a multi-objective optimization problem is used in order to maximize the damping ratio of electromechanical modes, matching different numbers of PSSs with a UPFC. An application of evolutionary algorithms to optimal siting and sizing of UPFC is presented in [24], which are formulated as single and multi-objective optimization problems such as enhancement of the loadability limit. The low frequency oscillations damping of a SMIB power system which includes a UPFC is presented in [25], which based on adaptive back-stepping control the UPFC injected control inputs are designed based on Lyapunov stability theory. A comprehensive load flow model for the UPFC is presented in [26], which has the capability to control active and reactive powers and voltage magnitude simultaneously. The firefly algorithm and cuckoo search algorithm based on optimal location and the capacity of UPFC to improve the dynamic stability of the power system are proposed in [27], which the firefly algorithm technique optimizes the maximum power loss line as the suitable location of the UPFC. A dynamic model of UPFC to improve the power transfer capability through the transmission line is developed in [28], which shunt and series controllers are designed with fuzzy logic controller as a stand-alone module in PSCAD environment.

Today and in the future, the sharing of renewable energy sources of electricity generation is show a continuous significant increase the role of renewable sources in world. SO far various studies have been done on the application of FACTS devices in the energy system $[29,30]$. The use of the UPFC in order to improve the stability margin and also to damp out the power fluctuations in a combined wind and wave energy production system connected to bulk power network has been shown in [31]. A reliable optimization approach based on step by step variation to optimally allocate the TCSC and UPFC with wind generator under deregulated power system is presented in [32], which the proposed method for optimal placement of TCSC and UPFC has been tested and analyzed on modified IEEE 14-bus and modified IEEE 118-bus power systems.

In this paper, the application of UPFC in power flow control in power system is investigated. Phasor model of UPFC is used. MATLAB Simulink software package is used for the simulations. The system performance with different types of faults is analyzed and compared without and with UPFC controller.

\section{UNIFIEd POWER Flow CONTROLler}

In actually, combined shunt and series controllers inject current into the system with the shunt part of the controller and voltage in the line with the series part of the controller. The UPFC can provide simultaneously or selectively control of all real and reactive power flow and voltage amplitude at the point of common coupling [33]. The basic system configuration of UPFC structure is shown in Fig. 2. The UPFC is the combination of two voltage-source converters: first converter is connected to the power system through a shunt transformer (ET), whereas the second one converter is inserted into the transmission line through a series transformer (ST). It is a multi-converter based FACTS device that combines the operating principle of a STATCOM and a SSSC that are coupled on the common dc link capacitor. Each converter can independently generate or absorb reactive power. Also the control of each converter is taken up individually.

International Journal of Research Studies in Electrical and Electronics Engineering (IJRSEEE) Page | 6 
Table1. Facts controllers

\begin{tabular}{|l|l|l|l|}
\hline Device & Type & Device principle & Basic control \\
\hline SSSC & Series & reactive source & line compensation \\
\hline STATCOM & Shunt & reactive source & line voltage \\
\hline UPFC & shunt-series & $\begin{array}{l}\text { reactive source and } \\
\text { series compensation }\end{array}$ & $\begin{array}{l}\text { line compensation bus voltages } \\
\text { active power flow }\end{array}$ \\
\hline
\end{tabular}

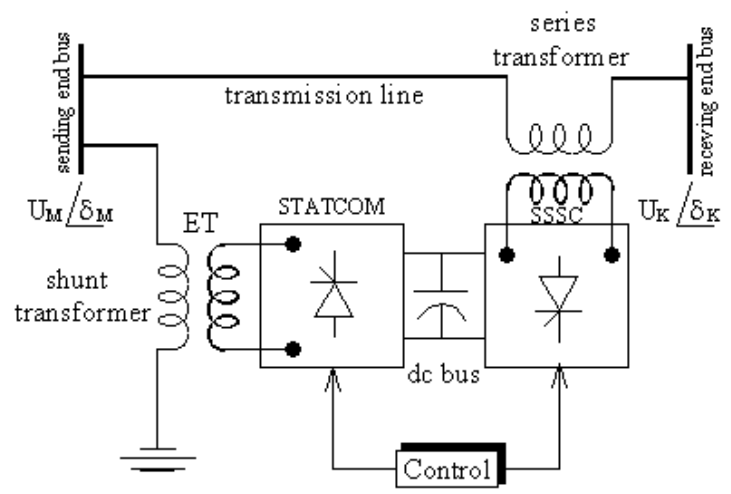

Fig2. Main circuit configuration of the UPFC system

\section{SYSTEM UNDER STUDY}

In order to study the performance of the UPFC controller, simulations have been performed for the Matlab Simulink implementation test system model in Fig. 3. It consists two power plants located on the buses B1 and B4, five buses B1 to B5 interconnected through three transmission lines L1, L2 and L3, two transformer banks T1 and T2 and two loads connected at buses B3 and B5.

The loop configuration of the two-machine power system in this study, where the synchronous generators G1 and G2 are delivering power to the a $200 \mathrm{MW}$ load connected at bus B3 and an $500 \mathrm{KV}$, 15000 MVA equivalent at bus B5 through three transmission lines L1, L2 and L3. T1 and T2 are the equivalent main transformer of system, respectively.

A UPFC is used to control the power flow in a $500 \mathrm{KV} / 230 \mathrm{KV}$ transmission system. The UPFC located at the right end of the $50 \mathrm{Kmline} \mathrm{L} 2$, between the $500 \mathrm{kV}$ buses B-UPFC and B3, is used to control the active and reactive powers flowing through bus B3 while controlling voltage at bus B-UPFC.

UPFC consists two converters, one connected in series between buses B1 and B2 and one connected in shunt at bus B1. The series converter can inject a maximum of $10 \%$ of nominal line-to-ground voltage $(28.87 \mathrm{kV})$ in series with line $\mathrm{L} 2$. The plant models include a speed regulator, an excitation system as well as a power system stabilizer (PSS) [34].

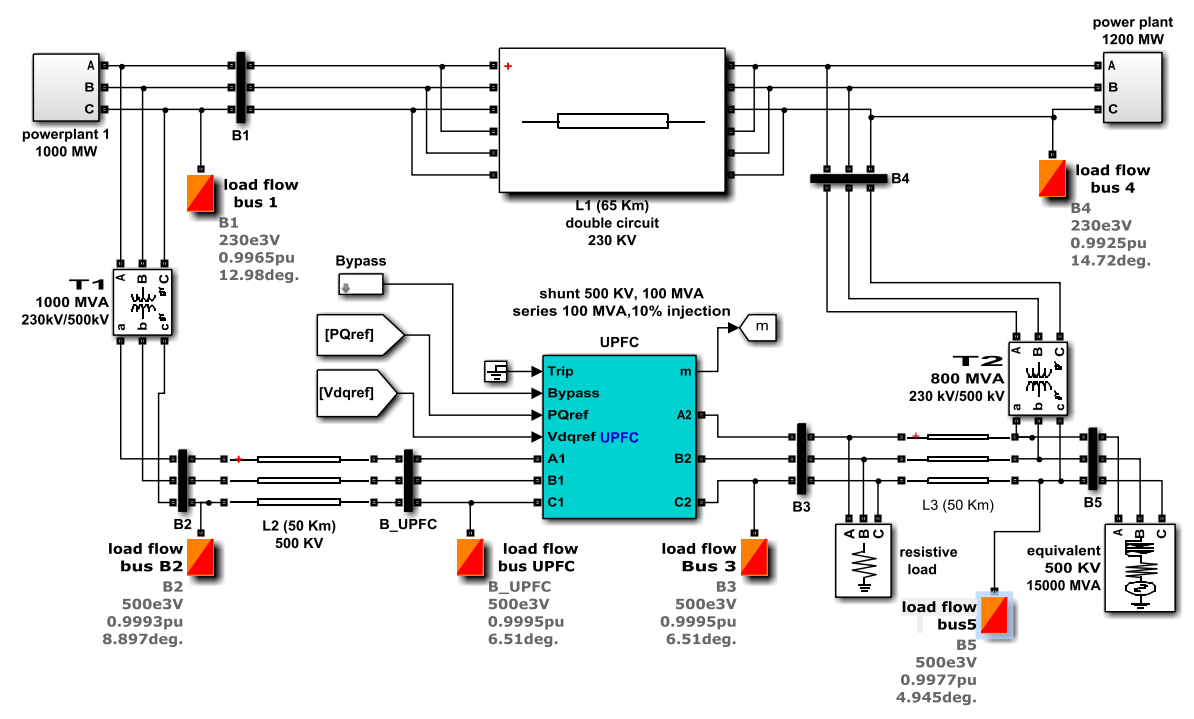

Fig3. MATLAB implementation of the test system 


\section{Simulation ReSUlts}

A UPFC phasor model of two 100 MVA, IGBT based converters is used. The block diagram of two power plants are shown in Figs. 4 and 5. The inside the block Reg-M1 is show in Fig. 6.

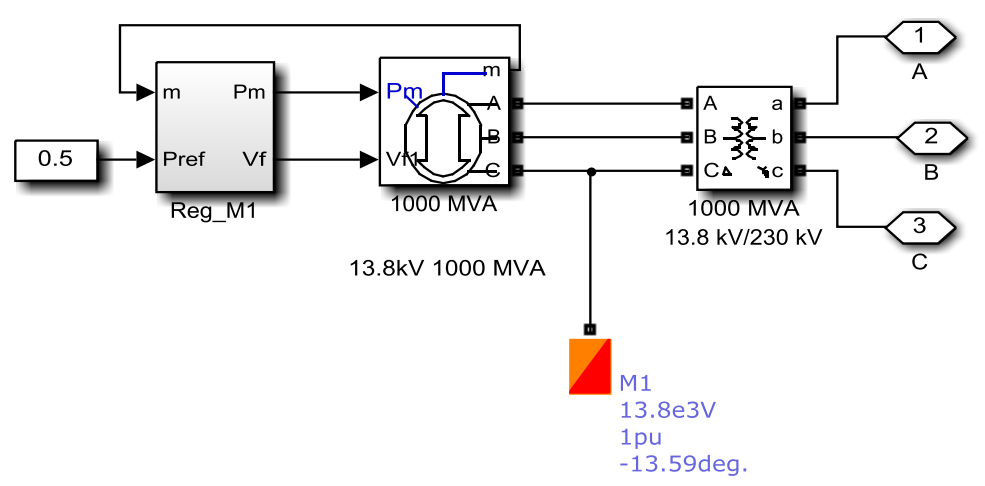

Fig4. Power plant 1 in Matlab/Simulink

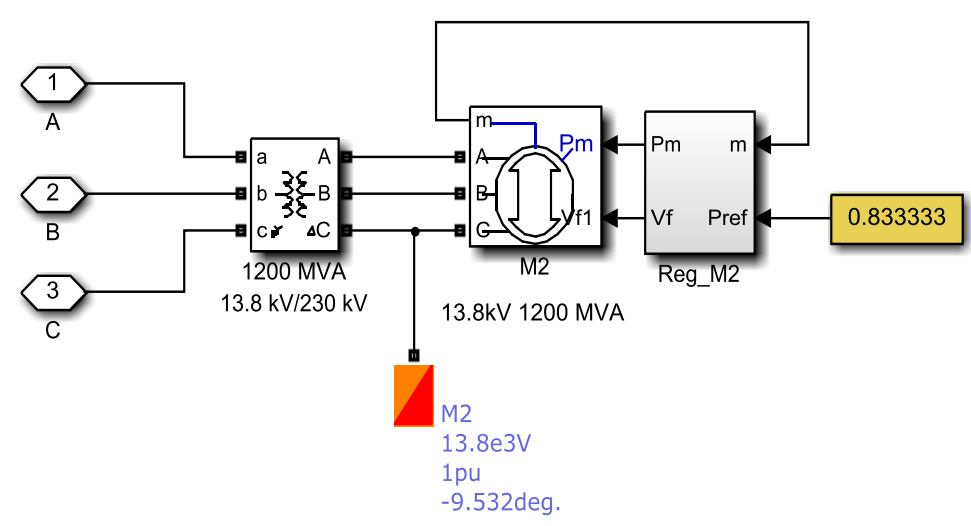

Fig5. Power plant 2 in Matlab/Simulink

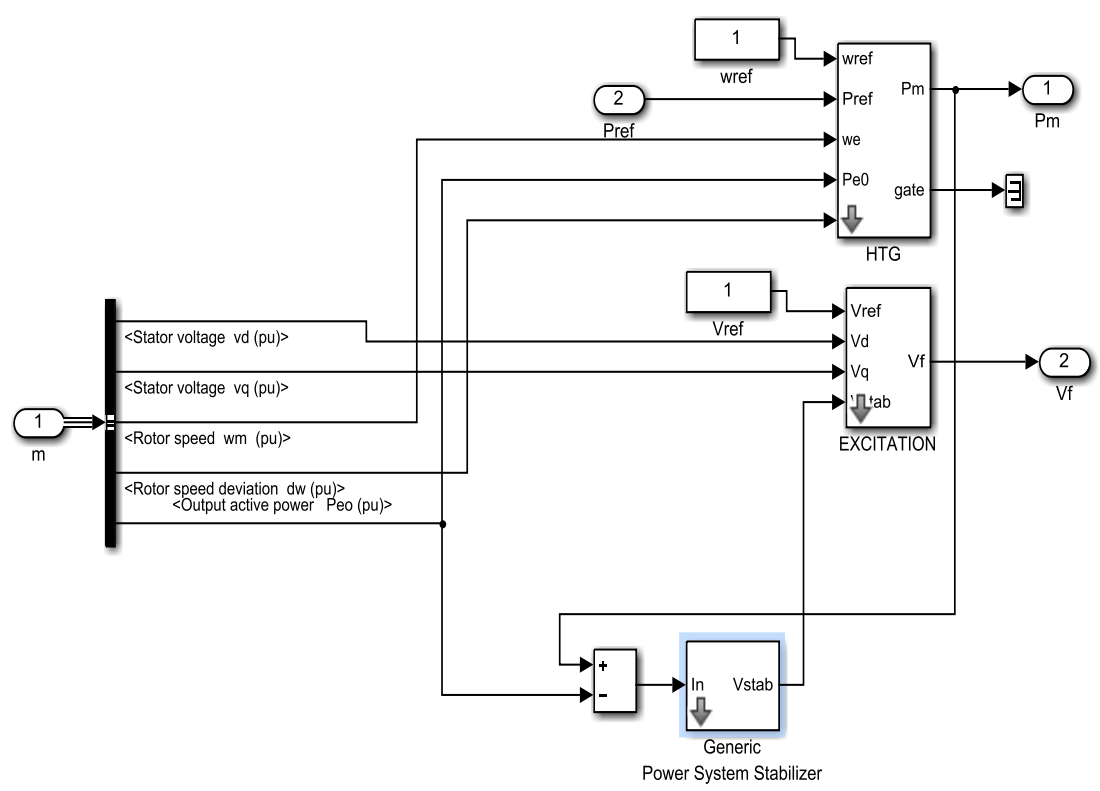

Fig6. View inside the block Reg-MI

Different types of faults like single line to ground, double line to ground and triple line to ground faults is analyzed and compared without and with controller. Voltage buses B1 and B4 is $500 \mathrm{KV}$ and voltage buses B2, B3 and B5 is $230 \mathrm{KV}$. Load at bus B5 is $500 \mathrm{KV}, 15000 \mathrm{MVA}$ and Load at bus B3 is $500 \mathrm{KV}$, 200MW. Power plant 1 is $13.8 \mathrm{KV}, 1000 \mathrm{MVA}$ and Power plant 2 is $13.8 \mathrm{KV}, 1200 \mathrm{MVA}$. Line 1 is a 
double circuit, $230 \mathrm{KV}, 65 \mathrm{Km}$ and lines 2 and 3 are $50 \mathrm{Km}, 500 \mathrm{KV}$. Transformer banks $\mathrm{T} 1$ is $1000 \mathrm{MVA}, 500 \mathrm{KV} / 230 \mathrm{KV}$ and transformer banks T2 is $800 \mathrm{MVA}, 500 \mathrm{KV} / 230 \mathrm{KV}$.

The voltage generated by the series inverter is controlled by two external signals. The power regulator gains are $\mathrm{KP}=0.025$ and $\mathrm{KI}=1.5$. Maximum rate of change for reference active power and reactive power are $1 \mathrm{pu} / \mathrm{s}$. Initially the bypass breaker is closed and the resulting natural power flow at bus B3 is 587 MW and -27 MVar. The blue numbers on the block diagram of the power system with UPFC in service, show the power flow with controlling the B3 active and reactive powers respectively at $687 \mathrm{MW}$ and 27 MVar. The trajectory of the UPFC reactive power as function of its active power, measured at bus B3 is show in Fig. 7.

The area located inside the ellipse represents the UPFC controllable region. For the first five seconds the PQ trajectory stays at the -27Mvar, 587 MW point (bypass breaker stays closed).

The magnitude and phase of the injected series voltage are shown in Figs. 8 and 9. When the breaker opens, the magnitude of the injected series voltage is ramped, from 0.0094 to $0.1 \mathrm{pu}$. At $10 \mathrm{~s}$, the angle of the injected voltage starts varying at a rate of 45 degree/s.Fig. 10 show the reactive power measured at bus B3 follow the reference values. At $\mathrm{t}=5 \mathrm{~s}$, when the bypass breaker is opened the natural power is diverted from the bypass breaker to the UPFC series branch without noticeable transient. The variations of active powers at buses B1, B2, B4 and B5 is show in Fig. 11 and the variations of reactive powers at buses B1, B2, B4 and B5 is show in Fig. 12.

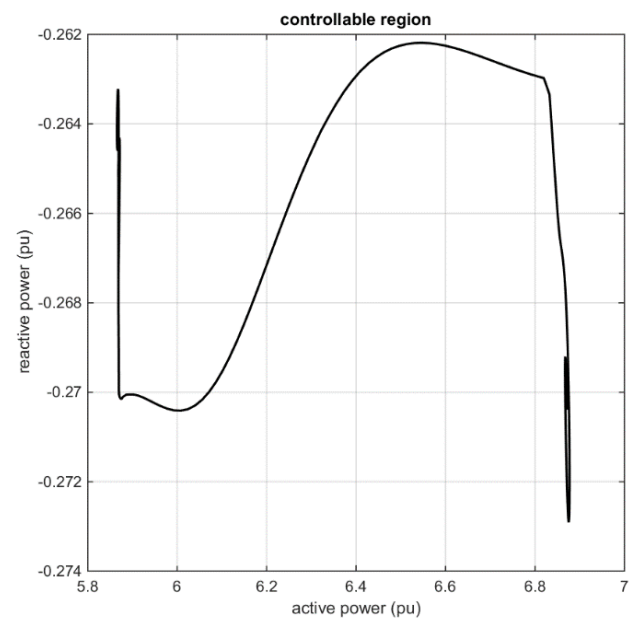

Fig7. UPFC controllable region

The power increases at a rate of $1 \mathrm{pu} / \mathrm{s}$ at $\mathrm{t}=10 \mathrm{~s}$. It takes one second for the power to increase to 687 MW. This $100 \mathrm{MW}$ increase of active power at bus B3 is achieved by injecting a series voltage of 0.089 pu with an angle of 94 degrees. This results in an approximate $100 \mathrm{MW}$ decrease in the active power flowing through T2 (from $899 \mathrm{MW}$ to $796 \mathrm{MW}$ ), which now carries an acceptable load. The excitation voltage and mechanical power in power plant one are shown in Figs. 13 and 14. The excitation voltage and mechanical power in power plant two are shown in Figs. 15 and 16.

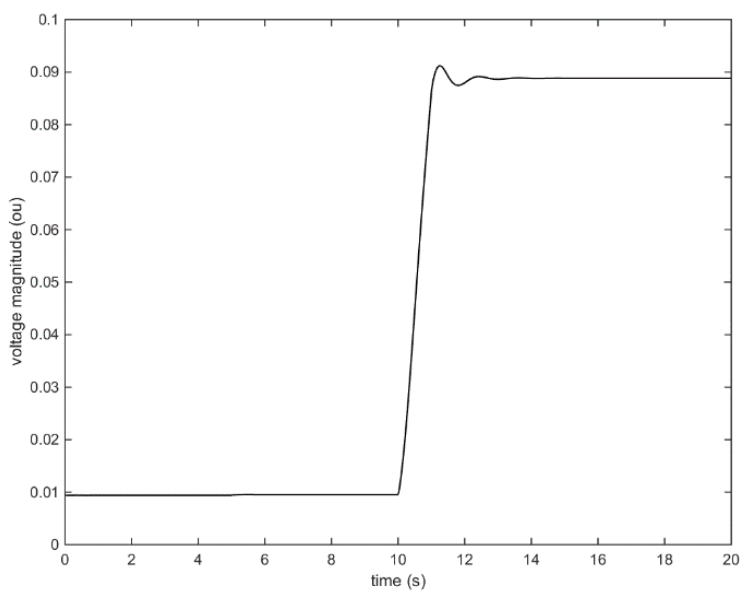

Fig8. Magnitude of the injected series voltage 


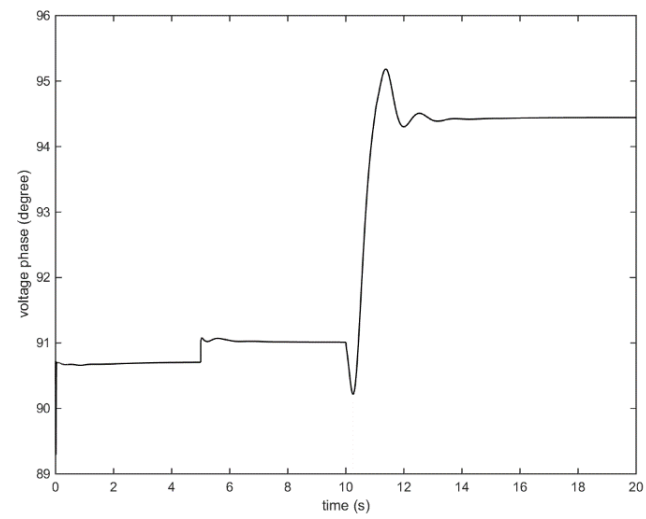

Fig9. Phase the injected series voltage

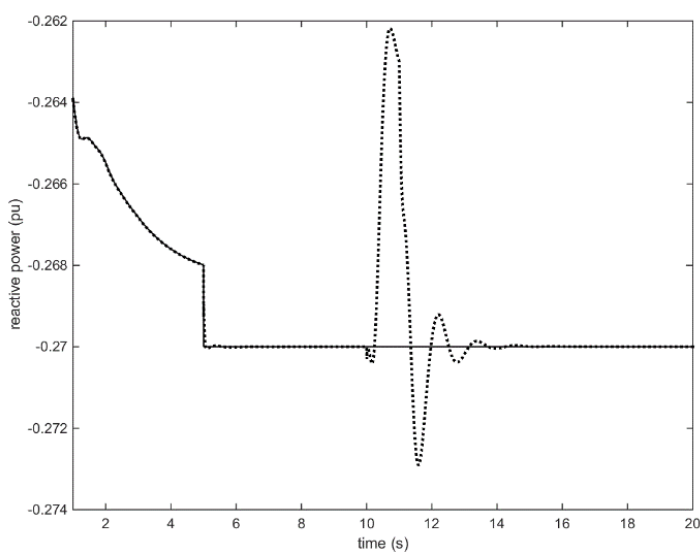

Fig10. Reactivw power measured at bus B3 follow the reference values

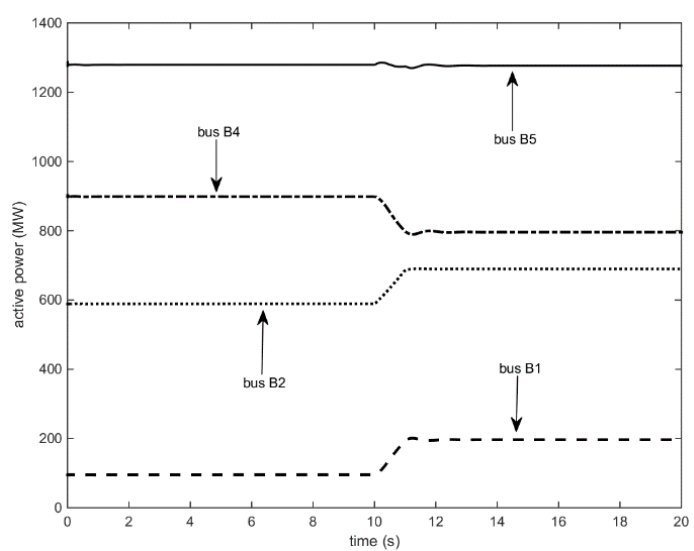

Fig11. Change of active power at buses

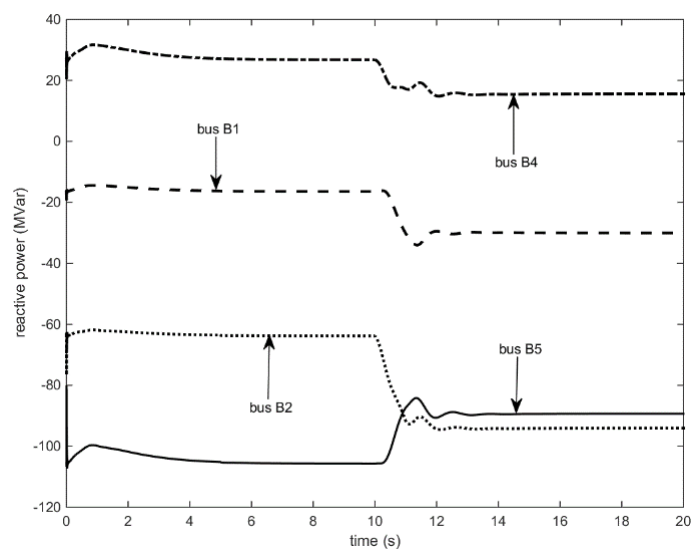

Fig12. Change of reactive power at buses 


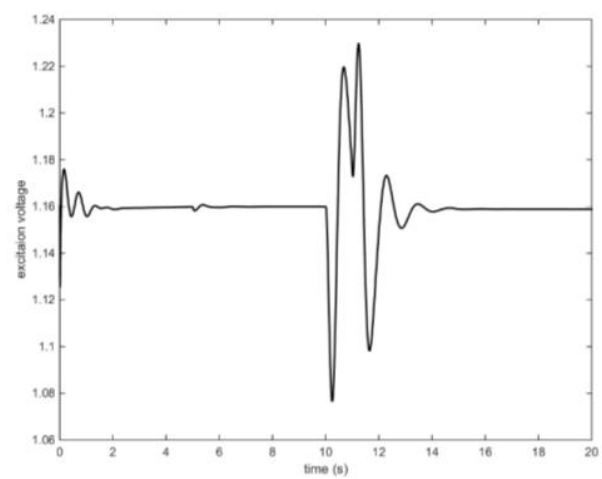

Fig13. Change of excitaion voltage in power plant one

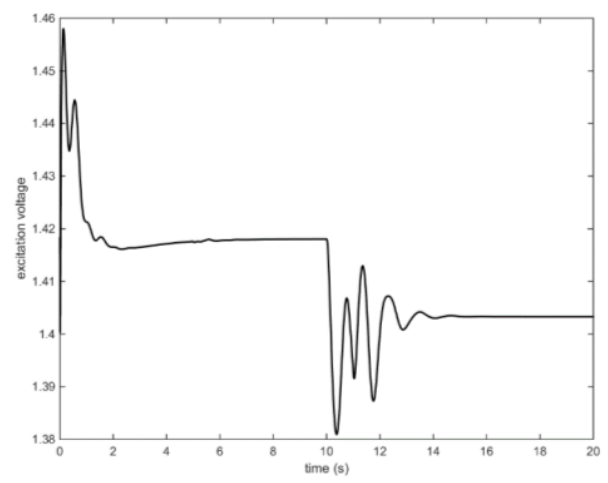

Fig14. Change of excitaion voltage in power plant two

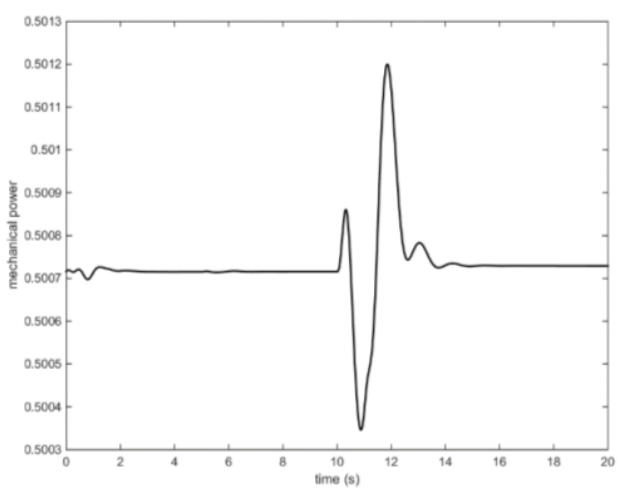

Fig15. Change of mechanical power in power plant one

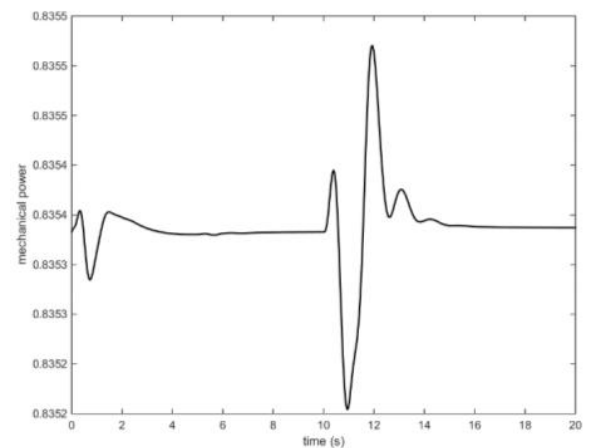

Fig16. Change of mechanical power in power plant two

\section{CONCLUSION}

Among FACTS controllers, UPFC is more promising due to its ability to work as series and shunt compensator together. UPFC is one of the most promising FACTS devices to power flow control and enhancing the stability. This paper describes the effect of UPFC to enhance the dynamic stability of power systems. UPFC can improve power system dynamic performance through its supplementary control. Different simulations are carried out in Matlab Simulink environment. 


\section{ACKNOWLEDGEMENT}

The authors would like to thank the journal editor and anonymous referees for their valuable comments and suggestions which effectively improved the quality of this paper. This research work was supported by Smart Microgrid Research Center, Najafabad Branch, Islamic Azad University, Najafabad, Iran.

\section{REFERENCES}

[1] G. Shahgholian, A. Etesami, "The effect of thyristor controlled series compensator on power system oscillation damping control", International Review of Electrical Engineering, Vol. 5, No. 2, pp. 1822-1830, Aug. 2011.

[2] G. Shahgholian, P. Shafaghi, S. Moalem, M. Mahdavian, "Damping power system oscillations in singlemachine infinite-bus power system using a STATCOM", Proceeding of the IEEE/ICCEE, pp.130-134, Dubai, Dec. 2009.

[3] G. Shahgholian, A. Movahedi, "Coordinated control of TCSC and SVC for system stability enhancement using ANFIS method", International Review on Modelling and Simulations, Vol. 4, No. 5, pp. 2367-2375, Oct. 2011.

[4] F. Mogharrab-Tehrani, G. Shahgholian, H. Pourghassem, "Dynamic study and stability analyze of damping cohefision and reactance in TCSC controller connected on optimization SMIB system", Proceeding of the IEEE/ ICCSN, pp. 270-274, China, May 2011.

[5] Z. Luburić, H. Pandžić, "FACTS devices and energy storage in unit commitment ", International Journal of Electrical Power and Energy Systems, Vol. 104, pp. 311-325, Jan. 2019.

[6] G. Shahgholian, H. Hamidpour, A. Movahedi, "Transient stability promotion by FACTS controller based on adaptive inertia weight particle swarm optimization method", Advances in Electrical and Electronic Engineering, Vol. 16, No. 1, pp. 57-70, March 2018.

[7] L.M. Castro, E. Acha, C.R. Fuerte-Esquivel, "A novel STATCOM model for dynamic power system simulations", IEEE Trans. on Power Systems, pp. 3145-3154, Vol. 28, No. 3, Aug. 2013.

[8] S. Fazeli-Nejad, G. Shahgholian, M. Moazzami, "Artificial bee colony algorithm based approach for power system oscillation damping with PSS and STATCOM", International Journal of Research Studies in Electrical and Electronics Engineering, Vol. 5, No. 2, pp. 27-39, 2019.

[9] S.M. Abd Elazim, E.S. Ali, "Optimal SSSC design for damping power systems oscillations via gravitational search algorithm", International Journal of Electrical Power and Energy Systems, Vol. 82, pp. 161-168, Nov. 2016.

[10] J. Bhukya, V. Mahajan, "Optimization of damping controller for PSS and SSSC to improve stability of interconnected system with DFIG based wind farm", International Journal of Electrical Power and Energy Systems, Vol. 108, pp. 314-335, June 2019.

[11] J. Guo, M.L. Crow, J. Sarangapani, "An improved UPFC control for oscillation damping", IEEE Trans. on Power Systems, Vol. 24, No. 1, Feb. 2009.

[12] G. Shahgholian, M. Mahdavian, M. Janghorbani, I. Eshaghpour, E. Ganji, "Analysis and simulation of UPFC in electrical power system for power flow control", Proceeding of the IEEE/ECTICON, pp. 62-65, Phuket, Thailand, June 2017.

[13] E. Jafari, A. Marjanian, S. Silaymani, Gh. Shahgholian, "Designing an emotional intelligent controller for IPFC to improve the transient stability based on energy function", Journal of Electrical Engineering \& Technology, Vol. 8, No. 3, pp. 478-489, 2013.

[14] G. Shahgholian, M. Mahdavian, M. Noorani-Kalteh, M.R. Janghorbani, "Design of a new IPFC-based damping neurocontrol for enhancing stability of a power system using particle swarm optimization", International Journal of Smart Electrical Engineering, Vol. 3, No. 2, pp. 73-78, Spring 2014.

[15] C.O. Maddela, B. Subudhi, "Robust wide-area TCSC controller for damping enhancement of inter-area oscillations in an interconnected power system with actuator saturation", International Journal of Electrical Power and Energy Systems, Vol. 105, pp. 478-487, Feb. 2019.

[16] [19-34] S. Dawn, P.K. Tiwari, A.K. Goswami, "An approach for long term economic operations of competitive power market by optimal combined scheduling of wind turbines and FACTS controllers", Energy, Vol. 181, pp. 709-723, Aug. 2019.

[17] S. Golshannavaz, F. Aminifar, D. Nazarpour, "Application of UPFC to enhancing oscillatory response of series-compensated wind farm integrations", IEEE Trans. on Smart Grid, Vol. 5, No. 4, pp. 1961-1968, July 2014.

[18] J. Li, F. Liu, Z. Li, S. Mei, G. He, "Impacts and benefits of UPFC to wind power integration in unit commitment", Renewable Energy, Vol. 116, Part A, pp. 570-583, Feb. 2018.

International Journal of Research Studies in Electrical and Electronics Engineering (IJRSEEE) Page | 12 
[19] M. Pereira, L.C. Zanetta, "A current based model for load flow studies with UPFC", IEEE Trans. on Power Systems, Vol. 28, No. 2, pp. 677-682, May 2013.

[20] J. Faiz, G. Shahgholian, M. Torabiyan, "Design and simulation of UPFC for enhancement of power quality in transmission lines", Proceeding of the IEEE/POWERCON, pp. 1-5, Hangzhou, Oct. 2010.

[21] S.O. Faried, R. Billinton, S. Aboreshaid, "Probabilistic technique for sizing FACTS devices for steady-state voltage profile enhancement", IET Gen., Trans. Dist., Vol. 3, No. 4, pp. 385-392, April 2009.

[22] M.A. Furini, A.L.S. Pereira,P.B. Araujo, "Pole placement by coordinated tuning of power system stabilizers and FACTS-POD stabilizers", International Journal of Electrical Power and Energy Systems, Vol. 33, No. 3, pp. 615-622, March 2011.

[23] L.H. Hassan, M. Moghavvemi, H.A.F. Almurib, K.M. Muttaqi, "A coordinated design of PSSs and UPFCbased stabilizer using genetic algorithm", IEEE Trans. on Ind. Appl., Vol. 50, No. 5, pp. 2957-2966, Feb. 2014.

[24] S. Alamelu, S. Baskar, C.K. Babulal, S. Jeyadevi, "Optimal siting and sizing of UPFC using evolutionary algorithms", International Journal of Electrical Power and Energy Systems, Vol. 69, pp. 222-231, 2015.

[25] S. Shojaeian, J. Soltani, "Low frequency oscillations damping of power system including unified power flow controller based on adaptive backstepping control", Revue Roumaine Des Sciences Techniques, Vol. 58, No. 2, pp. 193-204, 2013.

[26] K.A.K. Reddy, S.P. Singh, "Congestion mitigation using UPFC", IET Gen., Trans. Dist., Vol. 10, No. 10, pp. 2433-2442, July 2016.

[27] B. Vijay Kumar, N.V. Srikanth, "A hybrid approach for optimal location and capacity of UPFC to improve the dynamic stability of the power system", Applied Soft Computing, Vol. 52, pp. 974-986, March 2017.

[28] S. Ahmad, F.M. Albatsh, S. Mekhilef, H. Mokhlis, "Fuzzy based controller for dynamic unified power flow controller to enhance power transfer capability", Energy Conversion and Management, Vol.7 9, pp. 652665, March 2014.

[29] J. Shair, X.Xie, L.Wang, W. Liu, J.He, H. Liu, "Overview of emerging subsynchronous oscillations in practical wind power systems", Renewable and Sustainable Energy Reviews, Vol. 99, pp. 159-168, Jan. 2019.

[30] D.V.N. Ananth, G.V.N. Kumar, "Fault ride-through enhancement using an enhanced field oriented control technique for converters of grid connected DFIG and STATCOM for different types of faults", ISA Transactions, Vol. 62, pp. 2-18, May 2016.

[31] L. Wang, H. W. Li, C.T. Wu, "Stability analysis of an integrated offshore wind and seashore wave farm fed to a power grid using a unified power flow controller", IEEE Trans. on Power Systems, Vol. 28, No. 3, pp. 2211-2221, Aug. 2013.

[32] S. Dawn, P.K. Tiwari, "Improvement of economic profit by optimal allocation of TCSC \& UPFC with wind power generators in double auction competitive power market", International Journal of Electrical Power and Energy Systems, Vol. 80, pp. 190-201, Sep. 2016.

[33] A. Mohanty, S. Patra, P.K. Ray, "Robust fuzzy-sliding mode based UPFC controller for transient stability analysis in autonomous wind-diesel-PV hybrid system", IET Generation, Transmission and Distribution, Vol. 10, No. 5, pp. 1248-1257, April 2016.

[34] G. Shahgholian, "Review of power system stabilizer: Application, modeling, analysis and control strategy", Int. J. on Technical and Physical Problems of Engineering, Vol. 5, No. 3, pp. 41-52, Sep. 2013.

Citation: Ghazanfar Shahgholian \& Mohammad Reza Yousefi (2019). "Performance Improvement of Electrical Power System using UPFC Controller". International Journal of Research Studies in Electrical and Electronics Engineering (IJRSEEE), 5(3), pp 5-13. DOI: http://dx.doi. org/10.20431/2454-9436.0503002

Copyright: (C) 2019 Authors. This is an open-access article distributed under the terms of the Creative Commons Attribution License, which permits unrestricted use, distribution, and reproduction in any medium, provided the original author and source are credited. 